\title{
Mental Health \\ and \\ Substance Use
}

Substance Misuse in Depression and Bipolar Disorder: A Review of Psychological Interventions and Considerations for Clinical Practice.

\begin{tabular}{|r|l|}
\hline Journal: & Mental Health and Substance Use \\
\hline Manuscript ID: & Draft \\
\hline Manuscript Type: & Review \\
\hline Keywords: & $\begin{array}{l}\text { Bipolar Disorder, Depression, Substance Misuse, Drug Misuse, } \\
\text { Psychological Interventions }\end{array}$ \\
\hline \multicolumn{2}{|l}{} \\
\hline
\end{tabular}

\section{SCHOLARONE Manuscripts}




\section{Review Paper}

Title: Substance Misuse in Depression and Bipolar Disorder: A Review of Psychological Interventions and Considerations for Clinical Practice.

Author Affiliation: Thomas Richardson, Professional Training Unit, School of Psychology, University of Southampton, Southampton, U.K.

Correspondence: Thomas Richardson, Professional Training Unit, 34 Bassett Crescent East, Southampton, SO16 7PB, Hampshire, U.K. Email: thr1g10@ soton.ac.uk

Word Count: 4,982 (excluding abstract and references)

This paper has been accepted for publication after being initially submitted to the student 2011 essay competition. 


\title{
Substance Misuse in Depression and Bipolar Disorder: A Review of Psychological Interventions and Considerations for Clinical Practice.
}

\begin{abstract}
Research has documented high levels of co-morbidity between mental illness and substance misuse. This essay explores clinical practice issues relating to 'dual diagnosis' substance misuse in bipolar disorder and depression. Such misuse is common in this population, and presents a number of challenges to clinicians. Those with substance misuse have more severe symptoms and an increased risk of relapse. Assessment is complicated by factors such as a lack of standardised measures specifically for use with dual diagnosis clients. The effectiveness of specific psychological interventions for this population is somewhat unclear, though integrated interventions where both problems are treated together are often used. CBT has been used with depression and substance use though its effectiveness with bipolar is unclear, and motivational interviewing is often used as a supplement to this. Integrated group interventions are being developed and appear to be superior to groups focusing on substance use alone. Other therapeutic such as Acceptance and Commitment therapy are starting to be developed for use with dual diagnosis clients. A number of variables predict outcome from interventions, and there may be considerable gender differences which need to be taken into account. At present integrated dual diagnosis services are developing slowly within the National Health Service though there have been some notable service innovations in recent years. It is concluded that those with substance misuse in addition to bipolar disorder or depression need to be given special clinical consideration, though more research on how this can be effectively done is needed.
\end{abstract}

Keywords: Bipolar Disorder, Depression, Substance Misuse, Drug Misuse, Psychological Interventions. 


\section{Introduction}

In recent years there has been an increasing recognition that those with mental illness are at increased risk of having 'co-morbid' drug and alcohol problems, known collectively as 'substance misuse'. 'Dual diagnosis' is often used to refer to those with mental illness and substance misuse. Those with substance misuse may experience problems in functioning, put themselves in danger from their misuse and continue to use despite these negative problems (American Psychiatric Association, 2000). Those with 'dependence' develop tolerance and experience withdrawal symptoms, and have previously unsuccessfully tried to reduce their use (APA, 2000).

Those with dual diagnosis present a number of challenges to mental health professionals. This essay will discuss clinical practice issues relating substance misuse in bipolar disorder and depression. Depression is characterised by feelings of sadness, reduced interest in usual activities, sleep disturbances and loss of energy (APA, 2000). Those with bipolar disorder experience episodes of mania (Bipolar I disorder) or hypomania (Bipolar II disorder), usually with episodes of depression (APA, 2000). Hypomania and mania are characterised by symptoms such as impulsivity, racing thoughts, elevated mood and reduced need for sleep (APA, 2000).

This essay will discuss the challenges of working with clients with bipolar disorder or depression and co-morbid substance misuse, by emphasising the differences between those with and without substance misuse. The effect of substance misuse on symptoms and the complexities of assessment with this population are discussed, and current research on psychological interventions will be evaluated. Finally, other clinical considerations such as 
service issues will be discussed in order to illustrate the complexity of working with this population.

\section{Epidemiology of dual diagnosis}

\section{Prevalence of co-morbidity}

Research has shown that people with depression are four times as likely to have alcohol problems (Grant \& Harford, 1995), and those with bipolar disorder are eleven times more likely to have substance misuse disorders than those with no mental health problems (Regier et al., 1990). Bipolar disorder has higher levels of co-morbid substance misuse than any other Axis 1 mental illness (Regier, et al., 1990). A third have a current problem (Bauer et al., 2005), and the majority have had problems with drug or alcohol at some point in their lives (Bauer, et al., 2005; Levander et al., 2007). Research has also shown relationships between substance misuse and symptoms of depression (Van Laar, Van Dorsselaer, Monshouwer, \& De Graaf, 2007), mania (Henquet, Krabbendam, de Graaf, ten Have, \& van Os, 2006) and hypomania (Richardson \& Garavan, 2011), in the general population. In addition depression is present in $25 \%$ of those with alcohol dependence (Lyne, O'Donoghue, Clancy, \& O'Gara, 2011), and $43 \%$ of those with cocaine misuse (Brown et al., 1998). Thus there are high levels of substance misuse in those with depression and bipolar disorder, and high levels of depression in those with substance problems, suggesting co-morbidity is common in a range of clinical settings.

\section{Theoretical Explanations of Co-Morbidity}

A number of theories attempt to explain the relationship between mental illness and drug and alcohol misuse (Mueser, Drake, \& Wallach, 1998). Firstly, there are common factors, such as low socio-economic status, which increase vulnerability to both mental illness and substance 


\section{Impact of Substance Misuse}

\section{Effect on symptom severity and relapse}

Research has demonstrated that those with depression and substance misuse have more severe symptoms and have been symptomatic for longer (Howland et al., 2009), with half the likelihood of long-term recovery (Mueller et al., 1994), than those with depression only. Similarly, those with bipolar disorder and substance misuse have slower and poorer recovery from an acute affective episode (Gaudiano, Uebelacker, \& Miller, 2008; Goldberg, Garno, Leon, Kocsis, \& Portera, 1999; Weiss et al., 2005). Substance misuse also leads to an increased risk of relapse and rapid cycling (Ostacher et al., 2010), as well as severe mania and an increased likelihood of psychosis (van Rossum et al., 2009). This negative impact is seen even in those with remitted substance misuse (Gaudiano, et al., 2008). Thus those with substance misuse have more severe mood symptoms and an increased risk of relapse, suggesting the need for psychological interventions that address substance misuse.

\section{Importance of Self-medication}


Those with depression and bipolar disorder often misuse substances for self-medication of symptoms, and use specific drugs in attempt to alleviate specific symptoms (Blume, Schmaling, \& Marlatt, 2000; Weiss et al., 2004), or cope with stress (Healey, Peters, Kinderman, McCracken, \& Morriss, 2009). Importantly such beliefs about substance misuse appear to increase the risk of problematic use; Johnson and Gurin (1994) found that the comorbidity between depression and alcohol dependence was higher in those who believed alcohol would elevate their mood. Similarly drinking to cope in those with depression has been found to predict increased alcohol misuse 10 years later (Holahan, Moos, Holahan, Cronkite, \& Randall, 2003). It has therefore been suggested that unrealistic beliefs about the effectiveness of self-medication need to be assessed and tackled in therapy (Blume et al., 2000).

\section{Other correlates of substance misuse}

Those with bipolar disorder and alcohol dependence have poorer neuropsychological functioning (Shan et al., 2011), raising questions for ability to engage in therapy. There is also elevated impulsivity (Holmes et al., 2009), suggesting that interventions to tackle this may be useful. Substance misuse in bipolar disorder is linked to lower quality of life (Weiss, et al., 2005), poorer occupational functioning (Goetz et al., 2007), higher levels of aggression (Grunebaum et al., 2006), frequent suicide attempts and earlier symptom onset (Richardson, 2011). Alcohol misuse elevates suicide risk in those with depression (Yaldizli, Kuhl, Graf, Wiesbeck, \& Wurst, 2010) and bipolar disorder (Comtois, Russo, Roy-Byrne, \& Ries, 2004). Those with substance misuse are therefore high risk and may require more intense intervention and monitoring. There is also an increased likelihood of having a co-morbid anxiety disorder (Richardson, 2011), or personality disorder (Mazza et al., 2009), so appropriate psychological interventions for these may be needed. Finally, there appear to be 


\section{Medication Issues}

Medication is recommended by the National Institute of Clinical Excellence (NICE) for bipolar disorder (NICE, 2006) and severe or treatment resistant depression (NICE, 2009). However, those with co-morbid substance misuse are less compliant with medication regimes (van Rossum, et al., 2009), and have a greater risk of complications such as anti-depressant induced hypomania (Goldberg \& Whiteside, 2002). There are few controlled trials on the effectiveness of medications for depression or bipolar disorder with substance misuse (Azorin et al., 2010; Torrens, Fonseca, Mateu, \& Farré, 2005), and medications for depression and substance misuse are more effective when psychosocial interventions are also used (Nunes \& Levin, 2004). Therefore there is an increased need for psychological interventions with this population. This essay will now look at issues relating to diagnosis and assessment in this population.

\section{Assessment and Diagnostic Issues}

\section{Primary/Secondary Distinction}

Whilst the term 'dual diagnosis' suggests an equal emphasis on the mood disorder and substance misuse, diagnostic classification systems rely on defining a primary and secondary diagnosis (APA, 2000). However, research has found that the primary/secondary distinction does not predict outcomes from treatment (Hasin, Trautman, Miele, \& Samet, 1996), and whether the mood disorder or substance misuse is dominant changes over time (Crum, 
Brown, Liang, \& Eaton, 2001). Thus it has been suggested that interventions should focus on impaired functioning and distress regardless of specific diagnoses or models of aetiology (Schuckit et al., 1997).

\section{Challenges in Assessment}

Substance misuse is often missed in those with mental health problems (Weaver et al., 2003). Conversely, those using cocaine are frequently incorrectly diagnosed with bipolar disorder on the basis of mood instability (Goldberg et al., 2008), which is a feature of both bipolar disorder and dependence. There is also overlap between the symptoms of depression and drug withdrawal, so separating the symptoms is complex (Myrick \& Brady, 2003). Incorrect assessments are often made when mood symptoms are assessed before detoxification (Goldberg, et al., 2008), so it is important to conduct assessments when patients are stable in mood and not under the influence (Whicher \& Abou-Saleh, 2007).

Research has shown that both mood symptoms and substance misuse are under-reported in the general population (Andrews, Henderson, \& Hall, 2001). However, work with dual diagnosis populations has shown that discrepancies between self-report and urine tests occur less than 5\% of the time (Weiss et al., 2007; Weiss et al., 1998). It has been suggested that self-report is more accurate when patients are not psychotic, with familiar staff, and where honesty about misuse is encouraged (Weiss, et al., 1998). Collateral reports from friends and family are often used to assess substance misuse; however research suggests that asking families may be of little value compared to self-report (Weiss, Greenfield, Griffin, Najavits, \& Fucito, 2000). 
Assessment needs to determine the age of onset of problems in order to determine whether mood symptoms or substance misuse came first (Kay-Lambkin, Baker, \& Carr, 2007). Due to high suicide risk (Comtois, et al., 2004; Yaldizli, et al., 2010) a risk assessment is vital. Discussing the frequency and duration of misuse may help identify triggers, and examining how substance misuse affects mood is important in developing a formulation (Kay-Lambkin, et al., 2007).

\section{Psychometric Tools}

The utility of commonly used psychometric tools with dual diagnosis patients is unclear. Tools such as the 'Chemical Use, Abuse and Dependence scale' and 'Dartmouth Assessment of Lifestyle Instrument' have adequate sensitivity and specificity in detecting substance misuse in those with mental illness (Appleby, Dyson, Altman, McGovern, \& Luchins, 1996; Rosenberg et al., 1998). The 'Psychiatric Research Interview for Substance and Mental Disorders' has been found to be reliable for detecting affective disorders in those with heavy drug and alcohol misuse (Hasin, et al., 1996).

The ‘Beck Depression Inventory’ (Beck, Ward, Mendelson, Mock, \& Erbaugh, 1961) can be used to distinguish substance misuse patients with or without depression (Lykke, Hesse, Austin, \& Oestrich, 2008), though it may have good sensitivity but poor specificity (Holtzheimer et al., 2010). A modified version (Beck, Steer, \& Brown, 2000) has a reduced focus on somatic symptoms, and therefore may have less overlap with substance withdrawal and be more appropriate for those with dual diagnosis (Kay-Lambkin, et al., 2007). A modified version of the 'Hamilton Depression Rating Scale' has good reliability when used with those with bipolar disorder and substance misuse (Kolodziej, Griffin, Bender, \& Weiss, 2008). The 'Centre for Epidemiological Studies Depression Scale' has limited overlap with 
substance misuse symptoms and can be used to detect depression, though it may be more accurate for those using alcohol than drugs (Eaton, Smith, Ybarra, Carles, \& Tien, 2004). The 'Substance Abuse Treatment Scale' can be used to assess treatment progress in those with dual diagnosis (McHugo, Drake, Burton, \& Ackerson, 1995), and measures of readiness to change can be used with dual diagnosis patients (Nidecker, DiClemente, Bennett, \& Bellack, 2008). Thus a number of questionnaires have been developed for use with dual diagnosis clients specifically, though for some questionnaires the reliability is unclear at present. This essay will now explore the effectiveness of specific psychological interventions for this dual diagnosis population.

\section{Psychological Interventions}

\section{Integrated Interventions}

In recent years interventions have changed from treating substance misuse and mental health separately to treating them together (Watkins, Hunter, Burnam, Pincus, \& Nicholson, 2005). Farren and McElroy (2008) have developed such an 'integrated' inpatient programme for those with bipolar or depression and substance misuse. This includes detoxification and mood stabilisation, followed by psychoeducation, individual therapy and group sessions with a relapse prevention focus. A case series demonstrated this intervention reduced substance misuse and improved affective symptoms (Farren \& McElroy, 2008).

Some reviews have concluded that integrated interventions are more effective than separate interventions (Drake \& Mueser, 2000; Reedy \& Hall, 2008). Though those with depression and substance misuse can be given addiction treatment alongside those with substance misuse alone (Galanter, Egelko, Edwards, \& Katz, 1996), those with depression have more severe dependence (Burns, Teesson, \& O'Neill, 2005; Leventhal, Mooney, DeLaune, \& Schmitz, 
Research suggests that integrated interventions for bipolar disorder reduce substance misuse but have little impact on affective symptoms (Drake, Xie, McHugo, \& Shumway, 2004). Due to little research and methodological limitations there is insufficient evidence at present to support the effectiveness of integrated interventions over treating substance misuse alone (Donald, Dower, \& Kavanagh, 2005; Hesse, 2009). Despite this a number of specific integrated interventions have been developed.

\section{Cognitive Behaviour Therapy}

Cognitive Behaviour Therapy (CBT) is recommended for bipolar disorder (NICE, 2006) and Depression (NICE, 2009). However, many randomised controlled trials exclude those with current (Lam, Hayward, Watkins, Wright, \& Sham, 2005; Lam et al., 2003), or past (Kessler et al., 2009) substance misuse. Recent research has begun to adapt CBT for those with comorbid substance misuse, using CBT to address thoughts and behaviours which underlie both mood and substance problems. These include elements such as mood, substance misuse and craving monitoring, scheduling activities unrelated to drug misuse, working on automatic thoughts, problem solving, relapse prevention, and social skills and assertiveness training (Baker \& Velleman, 2009; Brown, Evans, Miller, Burgess, \& Mueller, 1997; Lydecker et al., 2010). It has been suggested that an important component should be testing beliefs about the effectiveness of self-medication (Blume et al., 2000) 
Research has shown that integrated CBT reduces both substance misuse and depression (Lydecker, et al., 2010), more so than focusing on either depression or substance misuse (Baker et al., 2010). CBT has also been found to improve depression in those with alcohol dependence (Brown, et al., 1997) and amphetamine misuse (Bauer, et al., 2005). A computerised CBT intervention has been found to be effective for those with depression and alcohol or cannabis problems (Kay-Lambkin, Baker, Lewin, \& Carr, 2009). Work suggests that improvements in depression are related to reduced substance misuse (Baker et al., 2005), and an increased perceived ability to cope with low mood without drinking (Ramsey, Brown, Stuart, Burgess, \& Miller, 2002). This suggests that work on beliefs about alcohol misuse and self-efficacy to control mood should be key components of CBT interventions. Despite encouraging results from individual studies, a recent systematic review concluded that the efficacy of CBT for depression with substance misuse is relatively unclear at present (Hides, Samet, \& Lubman, 2010).

There is even less research examining the effectiveness of CBT for bipolar disorder with substance misuse. Schmitz et al. (2002) found that CBT improved medication compliance, reduced treatment drop-out and moderately improved in affective symptoms. However, substance misuse was not reduced (Schmitz et al., 2002). Thus integrative CBT interventions have been developed but their evidence base is limited at present.

\section{Motivational Interviewing}

Motivational Interviewing (MI) has been adapted for those with dual diagnosis, with a focus on the pros and cons of change, and the relationship between mental health and substance misuse (Martino, Carroll, Kostas, Perkins, \& Rounsaville, 2002). Such motivational techniques have been found to increase appointment attendance in those with dual diagnosis 
(Swanson, Pantalon, \& Cohen, 1999), and reduce alcohol misuse in psychiatric inpatients (Hulse \& Tait, 2002). There has been little work applying this specifically to depression or bipolar disorder, though a small study without a control group showed that MI for those with cocaine dependence and depression increased treatment adherence (Daley, Salloum, Zuckoff, Kirisci, \& Thase, 1998). MI components have also been used alongside CBT for those with mood and substance misuse problems (Baker \& Velleman, 2009; Kay-Lambkin, et al., 2009). A systematic review concluded that $\mathrm{MI}$ is the most effective intervention for reducing substance misuse in those with dual diagnosis, and combining this with CBT also improves mental health (Cleary, Hunt, Matheson, \& Walter, 2009). Thus MI may be useful to reduce drop out and improve substance misuse outcomes as part of a wider intervention.

\section{Group Interventions}

Group interventions developed for dual diagnosis can lead to improvements in both substance misuse and mental health (James et al., 2004). An integrated CBT group intervention has been developed specifically for those with depression and substance misuse (Osilla, Hepner, Munoz, Woo, \& Watkins, 2009), though its effectiveness has not yet been studied. Weiss, Najavits and Greenfield (1999) developed a 20-week relapse prevention group for those with bipolar disorder and substance misuse, which aimed to provide education, peer support and enhance motivation. An important component of these group interventions is the idea that similar thinking and behaviour patterns underlie both mood and drug problems (Weiss, 2004; Weiss, et al., 2007). The authors have tried to encourage such an integrative view by asking participants to consider themselves as having a diagnosis of 'bipolar substance misuse' (Weiss, 2004). This integrative focus includes discussing the effect of drug misuse on mood, coping with high risk situations and alternative ways to cope with mood symptoms (Weiss, et al., 1999). 
This group intervention has been found to reduce addiction severity and increase the likelihood of abstinence (Weiss et al., 2000). Whilst it leads to more pronounced improvements than group drug counselling on substance misuse outcomes, there is no difference on bipolar severity (Weiss, et al., 2007). A shortened version of this intervention has been shown to be superior to group drug counselling in reducing misuse (Weiss et al., 2009). It also reduced the risk of a depression relapse by $70 \%$, though the impact on mania was not as pronounced (Weiss, et al., 2009). This group intervention has been found to lead to improvements only in those who use drugs to self-medicate their affective symptoms (Weiss, et al., 2004). Thus it has been suggested that such interventions should be targeted at those who believe that substance misuse helps their mood (Weiss, et al., 2004).

\section{Other approaches}

A behavioural intervention where those with depression are given vouchers for attendance has been found to improve depression but not drug misuse (Carpenter, Aharonovich, Smith, Iguchi, \& Nunes, 2006). Brief sessions and phone contact with the client and their family improve medication adherence in those with bipolar and substance misuse (Gaudiano, Weinstock, \& Miller, 2011). Acceptance and Commitment Therapy has been adapted for use with depression and co-morbid alcohol misuse, though a small study showed improvements in depression were not greater than treatment as usual (Petersen \& Zettle, 2009). As substances are often misused to cope it has been suggested that teaching distress tolerance skills may be of use (Blume et al., 2000). This could be done using Dialectical Behaviour Therapy, which has shown promise when used with those with borderline personality disorder and co-morbid substance misuse (Linehan et al., 1999; van den Bosch, Verheul, Schippers, \& van den Brink). Mindfulness-Based Cognitive Therapy (MBCT) is 


\section{Considerations for Clinical Practice}

\section{Detoxification and Abstinence}

Polysubstance misuse is common in those with dual diagnosis (Gual, 2007). Some interventions require detoxification prior to therapeutic work (Farren \& McElroy, 2008), whilst others allow use so long as clients are not under the influence in sessions, and therapy is scheduled for times when substance misuse is unlikely (Carroll et al., 2009). It has been suggested that demanding abstinence prior to therapy will create a 'revolving door' scenario and reduce help-seeking, thus the goal of total abstinence may be unrealistic for those with dual diagnosis and the focus should be on harm reduction (Blume et al., 2000).

\section{Predictors of outcome}

Outcomes after dual diagnosis are better for those with higher cognitive functioning (Hunt, Baker, Michie, \& Kavanagh, 2009), suggesting that those with poor functioning should be offered more intense treatment and monitored carefully. Outcomes are also improved in those 
with higher levels of social support (Warren, Stein, \& Grella, 2007), and higher self-efficacy (Glasner-Edwards et al., 2007; Warren, et al., 2007). Thus work on social skills, and attempts to increased perceived self-efficacy over problems may be effective. Longer time spent in treatment and higher attendance also predicts greater improvements (Lydecker, et al., 2010; Warren, et al., 2007) so motivational interventions to increase attendance are important.

Outcomes are poorer for those who are younger (Farren \& McElroy, 2008; Graff, Griffin, \& Weiss, 2008), less educated (Graff, et al., 2008), unemployed (Farren \& McElroy, 2010) or from an ethnic minority group (Carpenter, et al., 2006). Those who have more severe affective symptoms (Farren \& McElroy, 2008), or a recent mood episode (Graff et al., 2008) also have poorer outcomes indicating the importance of a stable mood prior to intervention. High levels of anxiety or a co-morbid anxiety disorder (Farren \& McElroy, 2010; Howland, et al., 2009; Nomarniukor \& Brown, 2009), appear to impair outcome so psychological interventions to improve anxiety may be efficacious. Those who have more severe substance misuse show less benefit from treatment (Graff, et al., 2008; Nomarniukor \& Brown, 2009; Stein et al., 2004; Warren, et al., 2007), indicating closer monitoring to prevent relapse. A measure of craving, the 'Obsessive Compulsive Drinking Scale' (Anton, Moak, \& Latham, 1996) has been found to predict relapse in those with depression or bipolar disorder and alcohol problems (Farren \& McElroy, 2010), thus this could be used to identify high risk clients. Stresses such as relationship and housing problems predict relapse in those with depression and substance misuse (Tate et al., 2008), thus coping skills to deal with these are important. Finally, the majority of relapses occur within two months after treatment (Tate, et al., 2008), so close monitoring after discharge and booster sessions are indicated.

\section{Gender differences}


A number of gender differences are present in those with dual diagnosis. Men under-report mood symptoms, whilst women under-report substance misuse (Andrews, et al., 2001). Men are more likely to be using drugs rather than alcohol (Westreich, Guedj, Galanter, \& Baird, 1997), and have more severe problems with a greater likelihood of poly substance misuse (Comtois \& Ries, 1995). On the other hand women are less likely to attend groups (Comtois \& Ries, 1995). In those with depression and alcohol problems, if integrated interventions are not available then women respond better to a focus on depression, whereas men respond better to a focus on alcohol (Baker, et al., 2010). Thus different interventions may be required based on gender.

\section{Service level issues}

Mental health problems are common in drug and alcohol services, but are rarely documented (Cole \& Sacks, 2008), whilst substance misuse is common but often missed in mental health settings (Weaver et al., 2003). Weaver et al. (2003) found that $44 \%$ of those seen by Community Mental Health Teams (CMHTs) had substance misuse, and 75\% of those in drug and alcohol services had a mental health problem, but these were rarely detected. Research suggests that there are often few differences between dual diagnosis patients presenting to either mental health or addiction services (Havassy, Alvidrez, \& Owen, 2004). Thus those with dual diagnosis can present to both mental health and addiction services.

Dual diagnosis services are developing slowly in the U.K. National Health Service (NHS), perhaps due to no specific models being identified in the National Service Framework (Lowe \& Abou-Saleh, 2004). The Department of Health (2002) suggests that those with dual diagnosis should be offered integrated care within mental health services, with specialist addiction support only when essential as moving between services may increase the risk of 
drop out. The NICE guidelines for bipolar disorder similarly state that co-morbid substance should be treated within mental health services (NICE, 2006).

The Department of Health (2002) suggests that staff in mental health settings should be given dual diagnosis training, indicating a training role for clinical psychologists and other dual diagnosis specialists. Such training has been offered to some U.K. assertive outreach teams with beneficial effects (Graham, 2004; Graham et al., 2006). Recent dual diagnosis service innovations of note include the COMPASS service in Birmingham which combines psychosis and substance misuse treatment (Graham et al., 2003) and the Haringey dual diagnosis service which aims to bring dual diagnosis insights to mental health teams, and help transfer between services (Lowe \& Abou-Saleh, 2004).

\section{Summary of Clinical Implications}

Co-morbid substance misuse is common in depression and bipolar disorder and is associated with a number of negative outcomes. Thus it is important to screen those with depression and bipolar disorder for drug and alcohol misuse. Increased suicide risk, aggression, psychosis and impulsivity require close monitoring and appropriate risk assessments to be conducted. Those who are male, younger, unmarried, and have an anxiety or personality disorder are especially high risk for substance misuse and appropriate preventative interventions may be warranted.

It may be unclear what the 'primary' problem is though this is of limited importance for therapy. Assessments are best completed during times of stable mood and no acute intoxication. Self-report is usually accurate if patients are stable and collateral reports may have little additional benefit. Care is required when using standardised measures as many 
have not been validated for use with dual diagnosis populations. Only appropriately validated measures such as the 'Chemical Use, Abuse and Dependence scale' should be used to screen for substance misuse in those with mental illness. In those with substance misuse, depression should be screened for using specifically modified versions of questionnaires such as the 'Hamilton Depression Rating Scale'.

Evidence is somewhat limited at present, but integrated interventions where mood symptoms and substance misuse are tackled together may be effective. Integrated CBT can be used with depression and substance misuse but there is little work relating to bipolar disorder. CBT appears to be especially effective if beliefs about substance misuse and self-efficacy are targeted, and motivational interviewing should be used as in addition to psychological therapy. Group interventions which use psychoeducation and peer support with a relapse prevention approach appear to be effective though the evidence is better for bipolar disorder than depression. These should include assertiveness and social skills training, and try to tackle beliefs about the effectiveness of self-medication. Other approaches such as MBCT need to be specifically adapted and researched before use with this population.

Clinicians' should emphasise harm reduction rather than total abstinence, though acute intoxication may interfere with therapy. Relapse is common and ongoing monitoring and care is required. Those with poor cognitive functioning, younger, of low socio-economic or ethnic minority status may have poorer outcomes so require extra intervention. More severe affective symptoms also lead to poorer outcomes so stabilisation of mood prior to intervention is warranted. Addiction severity and craving should also be assessed as they increase the risk of relapse. Clinicians' should be aware of gender differences and may need to focus more on substance misuse in men. Finally, integrated care should be offered within 
CMHTs where possible, though staff in all clinical settings should be trained in dual diagnosis.

\section{Conclusion}

This essay has explored issues relating to working with co-morbid substance misuse in those with depression and bipolar disorder. Conclusions are limited to an extent as some issues discussed here relate to dual diagnosis in general, and there is often little research on depression and bipolar disorder specifically, despite the high levels of co-morbidity in this population. Previous reviews have similarly concluded that there is insufficient work on the effectiveness of dual diagnosis interventions for specific mental health problems (Tiet \& Mausbach, 2007). In addition some therapeutic techniques have not yet been adapted for dual diagnosis work. Research so far often suffers from methodological problems such as short follow-up periods and small samples (Horsfall, Cleary, Hunt, \& Walter, 2009).

However it is clear that substance misuse is common in depression and bipolar disorder, and such misuse has a number of negative effects. Co-morbid substance misuse therefore poses a number of challenges to clinicians, and the differences between those with and without substance use need to be taken into account. The necessity of integrated treatment is currently ambiguous and the effectiveness of a number of dual diagnosis interventions is unclear due to little research. Similarly dual diagnosis services in the U.K. are developing slowly and where such clients fit within the NHS is somewhat uncertain at present. Additional research on depression and bipolar disorder specifically will help better understand the clinical implications of dual diagnosis and assist the development of specific assessment and intervention techniques for this population. This will allow in turn for the development of more effective dual diagnosis services. 


\section{References}

American Psychiatric Association. (2000). Diagnostic and Statistical Manual of Mental Disorders, Fourth Edition, Text Revision. Washington DC: American Psychiatric Association.

Andrews, G., Henderson, S., \& Hall, W. (2001). Prevalence, comorbidity, disability and service utilisation. Overview of the Australian National Mental Health Survey. British Journal of Psychiatry, 178, 145-153.

Anton, R.F., Moak, D.H., \& Latham, P.K. (1996). The Obsessive Compulsive Drinking Scale: A New Method of Assessing Outcome in Alcoholism Treatment Studies. Archives of General Psychiatry, 53(3), 225-231.

Appleby, L., Dyson, V., Altman, E., McGovern, M., \& Luchins, D. (1996). Utility of the chemical use, abuse, and dependence scale in screening patients with severe mental illness. Psychiatric Services, 47(6), 647-649.

Azorin, J.M., Bowden, C.L., Garay, R.P., Perugi, G., Vieta, E., \& Young, A. H. (2010). Possible new ways in the pharmacological treatment of bipolar disorder and comorbid alcoholism. Neuropsychiatric Disease and Treatment, 6, 37-46. doi: 10.2147/NDT.S6741

Baker, A., Lee, N.K., Claire, M., Lewin, T.J., Grant, T., Pohlman, S., et al. (2005). Brief cognitive behavioural interventions for regular amphetamine users: a step in the right direction. Addiction, 100(3), 367-378. doi: 10.1111/j.1360-0443.2005.01002.x

Baker, A., \& Velleman, R. (2009). Helping non-specialist professionals to detect and assist with co-existing mental health and drug and alcohol problems. Mental Health and Substance Use: Dual Diagnosis, 2(3), 173 - 181. doi: 10.1080/17523280903200194 
Baker, A.L., Kavanagh, D.J., Kay-Lambkin, F.J., Hunt, S.A., Lewin, T.J., Carr, V.J., et al. (2010). Randomized controlled trial of cognitive-behavioural therapy for coexisting depression and alcohol problems: short-term outcome. Addiction, 105(1), 87-99. doi: 10.1111/j.1360-0443.2009.02757.x

Bauer, M.S., Altshuler, L., Evans, D.R., Beresford, T., Williford, W.O., Hauger, R., et al. (2005). Prevalence and distinct correlates of anxiety, substance, and combined comorbidity in a multi-site public sector sample with bipolar disorder. Journal of Affective Disorders, 85(3), 301-315.

Beck, A.T., Steer, R.A., \& Brown, G.K. (2000). BDI-II fast screen for medical patients manual. London: The Psychological Corporation.

Beck, A.T., Ward, C.H., Mendelson, M., Mock, J., \& Erbaugh, J. (1961). An inventory for measuring depression. Archives of General Psychiatry, 4, 561-571.

Blume, A.W., Schmaling, K.B., \& Marlatt, A.G. (2000). Revisiting the self-medication hypothesis from a behavioral perspective. Cognitive and Behavioral Practice, 7(4), 379-384. doi: 10.1016/S1077-7229(00)80048-6,

Brewer, J.A., Bowen, S., Smith, J.T., Marlatt, G.A., \& Potenza, M.N. (2010). Mindfulnessbased treatments for co-occurring depression and substance use disorders: what can we learn from the brain? Addiction, 105(10), 1698-1706. doi:10.1111/j.13600443.2009.02890.x

Brown, R.A., Evans, D.M., Miller, I.W., Burgess, E.S., \& Mueller, T. I. (1997). Cognitivebehavioral treatment for depression in alcoholism. Journal of Consulting and Clinical Psychology, 65(5), 715-726.

Brown, R.A., Monti, P.M., Myers, M.G., Martin, R.A., Rivinus, T., Dubreuil, M.E., et al. (1998). Depression Among Cocaine Abusers in Treatment: Relation to Cocaine and 
Alcohol Use and Treatment Outcome. American Journal of Psychiatry, 155(2), 220225.

Burns, L., Teesson, M., \& O'Neill, K. (2005). The impact of comorbid anxiety and depression on alcohol treatment outcomes. Addiction, 100(6), 787-796. doi: 10.1111/j.13600443.2005.001069.x

Carpenter, K.M., Aharonovich, E., Smith, J.L., Iguchi, M.Y., \& Nunes, E.V. (2006). Behavior Therapy for Depression in Drug Dependence (BTDD): Results of a Stage Ia Therapy Development Pilot. The American Journal of Drug and Alcohol Abuse, 32(4), 541-548. doi: 10.1080/00952990600919450

Carroll, S., Hides, L., Catania, L., Mathias, S., Greenwood-Smith, C., \& Lubman, D. (2009). Integrated cognitive behaviour therapy for co-occurring substance misuse and major depression: lessons from a youth mental health service. Australasian Psychiatry, 17(5), 365-370. doi: 10.1080/10398560902912544

Cleary, M., Hunt, G.E., Matheson, S., \& Walter, G. (2009). Psychosocial treatments for people with co-occurring severe mental illness and substance misuse: Systematic review. Journal of Advanced Nursing, 65(2), 238-258. doi: 10.1111/j.13652648.2008.04879.x

Cole, M., \& Sacks, T. (2008). When dual diagnosis means no diagnosis: co-occurring mental illness and problematic drug use in clients of alcohol and drug services in eastern metropolitan Melbourne. Mental Health and Substance Use: Dual Diagnosis, 1(1), 33 - 43. doi: 10.1080/17523280701747289

Comtois, K.A., \& Ries, R.K. (1995). Sex differences in dually diagnosed severely mentally ill clients in dual diagnosis outpatient treatment. The American Journal on Addictions, 4(3), 245-253. 
Comtois, K.A., Russo, J.E., Roy-Byrne, P., \& Ries, R.K. (2004). Clinicians' assessments of bipolar disorder and substance abuse as predictors of suicidal behavior in acutely hospitalized psychiatric inpatients. Biological Psychiatry, 56(10), 757-763. doi:10.1016/j.biopsych.2004.10.003

Crum, R.M., Brown, C., Liang, K.-Y., \& Eaton, W.W. (2001). The association of depression and problem drinking: Analyses from the Baltimore ECA follow-up study. Addictive Behaviors, 26(5), 765-773. doi: 10.1016/S0306-4603(00)00163-5

Curran, G.M., Booth, B.M., Kirchner, J.E., \& Deneke, D.E. (2007). Recognition and Management of Depression in a Substance Use Disorder Treatment Population. The American Journal of Drug and Alcohol Abuse, 33(4), 563-569. doi: $10.1080 / 00952990701407496$

Daley, D.C., Salloum, I.M., Zuckoff, A., Kirisci, L., \& Thase, M.E. (1998). Increasing Treatment Adherence Among Outpatients With Depression and Cocaine Dependence: Results of a Pilot Study. American Journal of Psychiatry, 155(11), 1611-1613.

Department of Health. (2002). Mental Health Policy Implementation Guide: Dual Diagnosis Good Practice Guide. London: Department of Health. Retrieved from: http://www.dh.gov.uk/en/Publicationsandstatistics/Publications/PublicationsPolicyAn dGuidance/DH_4009058

Dodge, R., Sindelar, J., \& Sinha, R. (2005). The role of depression symptoms in predicting drug abstinence in outpatient substance abuse treatment. Journal of Substance Abuse Treatment, 28(2), 189-196. doi: 10.1016/j.jsat.2004.12.005

Donald, M., Dower, J., \& Kavanagh, D. (2005). Integrated versus non-integrated management and care for clients with co-occurring mental health and substance use disorders: a qualitative systematic review of randomised controlled trials. Social Science \& Medicine, 60(6), 1371-1383. doi: 10.1016/j.socscimed.2004.06.052, 
Drake, R.E., \& Mueser, K.T. (2000). Psychosocial approaches to dual diagnosis. Schizophrenia Bulletin, 26(1), 105-118.

Drake, R.E., Xie, H., McHugo, G.J., \& Shumway, M. (2004). Three-Year Outcomes of LongTerm Patients with Co-occurring Bipolar and Substance Use Disorders. Biological Psychiatry, 56(10), 749-456. doi: 10.1016/j.biopsych.2004.08.020

Eaton, W.W., Smith, C., Ybarra, M., Carles, M., \& Tien, A. (2004). Center for Epidemiologic Studies Depression Scale: Review and Revision (CESD and CESD-R). In M. E. Maruish (Ed.), The use of psychological testing for treatment planning and outcomes assessment. Instrusment for adults. (pp. 363-378). Mahwah, New Jersey: Lawrence Erlbaum Associates.

Farren, C.K., \& McElroy, S. (2008). Treatment response of bipolar and unipolar alcoholics to an inpatient dual diagnosis program. Journal of Affective Disorders, 106(3), 265-272. doi: 10.1016/j.jad.2007.07.006

Farren, C.K., \& McElroy, S. (2010). Predictive factors for relapse after an integrated inpatient treatment programme for unipolar depressed and bipolar alcoholics. Alcohol and Alcoholism, 45(6), 527-533. doi: 10.1093/alcalc/agq060

Galanter, M., Egelko, S., Edwards, H., \& Katz, S. (1996). Can cocaine addicts with severe mental illness be treated along with singly diagnosed addicts? The American Journal of Drug and Alcohol Abuse, 22(4), 497-507.

Gaudiano, B.A., Uebelacker, L.A., \& Miller, I.W. (2008). Impact of remitted substance use disorders on the future course of bipolar I disorder: Findings from a clinical trial. Psychiatry Research, 160(1), 63-71. doi: 10.1016/j.psychres.2007.05.014

Gaudiano, B.A., Weinstock, L. M., \& Miller, I.W. (2011). Improving Treatment Adherence in Patients With Bipolar Disorder and Substance Abuse: Rationale and Initial 
Development of a Novel Psychosocial Approach. Journal of Psychiatric Practice, 17(1), 5-20. doi: 10.1097/01.pra.0000393840.18099.d6

Glasner-Edwards, S., Tate, S.R., McQuaid, J.R., Cummins, K., Granholm, E., \& Brown, S. A. (2007). Mechanisms of action in integrated cognitive-behavioral treatment versus twelve-step facilitation for substance-dependent adults with comorbid major depression. Journal of Studies on Alcohol and Drugs, 68(5), 663-672.

Goetz, I., Tohen, M., Reed, C., Lorenzo, M., \& Vieta, E. (2007). Functional impairment in patients with mania: baseline results of the EMBLEM study. Bipolar Disorders, $9(1-$ 2), 45-52. doi: 10.1111/j.1399-5618.2007.00325.x

Goldberg, J.F., Garno, J.L., Callahan, A.M., Kearns, D.L., Kerner, B., \& Ackerman, S.H. (2008). Overdiagnosis of bipolar disorder among substance use disorder inpatients with mood instability. Journal of Clinical Psychiatry, 69(11), 1751-1757.

Goldberg, J.F., Garno, J. L., Leon, A.C., Kocsis, J.H., \& Portera, L. (1999). A history of substance abuse complicates remission from acute mania in bipolar disorder. Journal of Clinical Psychiatry, 60(11), 733-740.

Goldberg, J.F., \& Whiteside, J.E. (2002). The association between substance abuse and antidepressant-induced mania in bipolar disorder: A preliminary study. Journal of Clinical Psychiatry, 63(9), 791-795.

Graff, F.S., Griffin, M.L., \& Weiss, R.D. (2008). Predictors of dropout from group therapy among patients with bipolar and substance use disorders. Drug and Alcohol Dependence, 94(1-3), 272-275. doi: 10.1016/j.drugalcdep.2007.11.002,

Graham, H. (2004). Implementing integrated treatment for co-existing substance use and severe mental health problems in assertive outreach teams: training issues. Drug \& Alcohol Review, 23(4), 463-470. doi: 10.1080/09595230412331324581 
Graham, H.L., Copello, A., Birchwood, M., Orford, J., McGovern, D., Georgiou, G., et al. (2003). Service innovations: Coexisting severe mental health and substance use problems: developing integrated services in the UK. Psychiatric Bulletin, 27(5), 183186.

Graham, H.L., Copello, A., Birchwood, M., Orford, J., McGovern, D., Mueser, K.T., et al. (2006). A preliminary evaluation of integrated treatment for co-existing substance use and severe mental health problems: Impact on teams and service users. Journal of Mental Health, 15(5), 577-591. doi:10.1080/09638230600902633)

Grant, B.F., \& Harford, T.C. (1995). Comorbidity between DSM-IV alcohol use disorders and major depression: results of a national survey. Drug and Alcohol Dependence, 39(3), 197-206. doi: 10.1016/0376-8716(95)01160-4,

Grunebaum, M.F., Galfalvy, H.C., Nichols, C.M., Caldeira, N.A., Sher, L., Dervic, K., et al. (2006). Aggression and substance abuse in bipolar disorder. Bipolar Disorders, 8(5 Pt 1), 496-502. doi: 10.1111/j.1399-5618.2006.00349.x

Gual, A. (2007). Dual diagnosis in Spain. Drug and Alcohol Review, 26(1), 65-71.

Hasin, D.S., Trautman, K.D., Miele, G.M., \& Samet, S. (1996). Psychiatric Research Interview for Substance and Mental Disorders (PRISM): Reliability for substance abusers. American Journal of Psychiatry, 153(9), 1195-1201.

Havassy, B.E., Alvidrez, J., \& Owen, K.K. (2004). Comparisons of Patients With Comorbid Psychiatric and Substance Use Disorders: Implications for Treatment and Service Delivery. American Journal of Psychiatry, 161(1), 139-145. doi: 10.1176/appi.ajp.161.1.139

Healey, C., Peters, S., Kinderman, P., McCracken, C., \& Morriss, R. (2009). Reasons for substance use in dual diagnosis bipolar disorder and substance use disorders: A 
qualitative study. Journal of Affective Disorders, 113(1-2), 118-126. doi: /10.1016/j.jad.2008.05.010

Henquet, C., Krabbendam, L., de Graaf, R., ten Have, M., \& van Os, J. (2006). Cannabis use and expression of mania in the general population. Journal of Affective Disorders, 95(1-3), 103-110. doi: /10.1016/j.jad.2006.05.002

Hesse, M. (2009). Integrated psychological treatment for substance use and co-morbid anxiety or depression vs. treatment for substance use alone. A systematic review of the published literature. BioMed Central Psychiatry, 9(1), 6. doi: 10.1186/1471-244X9-6

Hides, L., Samet, S., \& Lubman, D.I. (2010). Cognitive behaviour therapy (CBT) for the treatment of co-occurring depression and substance use: Current evidence and directions for future research. Drug and Alcohol Review, 29(5), 508-517. doi: 10.1111/j.1465-3362.2010.00207.x

Holahan, C.J., Moos, R.H., Holahan, C.K., Cronkite, R.C., \& Randall, P.K. (2003). Drinking to cope and alcohol use and abuse in unipolar depression: A 10-year model. Journal of Abnormal Psychology, 112(1), 159-165. doi: 10.1037/0021-843X.112.1.159

Holmes, M., Bearden, C.E., Barguil, M., Fonseca, M., Monkul, E.S., Nery, F.G., et al. (2009). Conceptualizing impulsivity and risk taking in bipolar disorder: importance of history of alcohol abuse. Bipolar Disorders, 11(1), 33-40. doi: 10.1111/j.13995618.2008.00657.x

Holtzheimer, P.E., Veitengruber, J., Wang, C.C., Krows, M., Thiede, H., Wald, A., et al. (2010). Utility of the Beck Depression Inventory to screen for and track depression in injection drug users seeking hepatitis C treatment. General Hospital Psychiatry, 32(4), 426-432. doi: 10.1016/j.genhosppsych.2010.02.001 
Hoppes, K. (2006). The application of mindfulness-based cognitive interventions in the treatment of co-occurring addictive and mood disorders. Cns Spectrums, 11(11), 829851. doi: 10.1016/j.genhosppsych.2010.02.001

Horsfall, J., Cleary, M., Hunt, G.E., \& Walter, G. (2009). Psychosocial Treatments for People with Co-occurring Severe Mental Illnesses and Substance Use Disorders (Dual Diagnosis): A Review of Empirical Evidence. Harvard Review of Psychiatry, 17(1), 24-34. doi: 10.1080/10673220902724599

Howland, R.H., John Rush, A., Wisniewski, S.R., Trivedi, M.H., Warden, D., Fava, M., et al. (2009). Concurrent anxiety and substance use disorders among outpatients with major depression: Clinical features and effect on treatment outcome. Drug and Alcohol Dependence, 99(1-3), 248-260. doi: 10.1016/j.drugalcdep.2008.08.010

Hulse, G.K., \& Tait, R.J. (2002). Six-month outcomes associated with a brief alcohol intervention for adult in-patients with psychiatric disorders. Drug \& Alcohol Review, 21(2), 105-112. doi: 10.1080/09595230220138993a

Hunt, S.A., Baker, A.L., Michie, P.T., \& Kavanagh, D.J. (2009). Neurocognitive profiles of people with comorbid depression and alcohol use: Implications for psychological interventions. $\quad$ Addictive Behaviors, 34(10), 878-886. doi: $10.1080 / 09595230220138993 a$

James, W., Preston, N.J., Koh, G., Spencer, C., Kisely, S.R., \& Castle, D.J. (2004). A group intervention which assists patients with dual diagnosis reduce their drug use: a randomized controlled trial. Psychological Medicine, 34(06), 983-990. doi: $10.1017 / \mathrm{S} 0033291703001648$

Johnson, P.B., \& Gurin, G. (1994). Negative affect, alcohol expectancies and alcohol-related problems. Addiction, 89(5), 581-586. doi: 10.1017/S0033291703001648 
Kay-Lambkin, F.J., Baker, A., \& Carr, V.J. (2007). Depression and drug and alcohol problems. In A.V. Baker \& R. Velleman (Eds.), Clinical handbook of co-existing mental health and drug and alcohol problems. (pp. 218-240). New York: Routledge/Taylor \& Francis Group.

Kay-Lambkin, F.J., Baker, A.L., Lewin, T.J., \& Carr, V.J. (2009). Computer-based psychological treatment for comorbid depression and problematic alcohol and/or cannabis use: a randomized controlled trial of clinical efficacy. Addiction, 104(3), 378-388. doi: 10.1111/j.1360-0443.2008.02444.x

Kessler, D., Lewis, G., Kaur, S., Wiles, N., King, M., Weich, S., et al. (2009). Therapistdelivered internet psychotherapy for depression in primary care: a randomised controlled trial. The Lancet, 374(9690), 628-634. doi: 10.1016/S0140-6736(09)61257$\underline{5}$,

Kolodziej, M.E., Griffin, M.L., Bender, R., \& Weiss, R.D. (2008). Assessment of depressive symptom severity among patients with co-occurring bipolar disorder and substance dependence. Journal of Affective Disorders, 106(1-2), 83-89. doi: 10.1016/j.jad.2007.05.024

Lam, D.H., Hayward, P., Watkins, E. R., Wright, K., \& Sham, P. (2005). Relapse Prevention in Patients With Bipolar Disorder: Cognitive Therapy Outcome After 2 Years. American Journal of Psychiatry, 162(2), 324-329.

Lam, D. H., Watkins, E. R., Hayward, P., Bright, J., Wright, K., Kerr, N., et al. (2003). A Randomized Controlled Study of Cognitive Therapy for Relapse Prevention for Bipolar Affective Disorder: Outcome of the First Year. Archives of General Psychiatry, 60(2), 145-152. doi: 10.1016/j.jad.2007.05.024

Levander, E., Frye, M.A., McElroy, S., Suppes, T., Grunze, H., Nolen, W.A., et al. (2007). Alcoholism and anxiety in bipolar illness: Differential lifetime anxiety comorbidity in 
bipolar I women with and without alcoholism. Journal of Affective Disorders, 101(13), 211-217. doi:10.1016/j.jad.2006.11.023

Leventhal, A.M., Mooney, M.E., DeLaune, K.A., \& Schmitz, J.M. (2006). Using Addiction Severity Profiles to Differentiate Cocaine-Dependent Patients with and without Comorbid Major Depression. American Journal on Addictions, 15(5), 362-369. doi: $10.1080 / 10550490600860148$

Linehan, M.M., Schmidt, H., Dimeff, L.A., Craft, J.C., Kanter, J., \& Comtois, K.A. (1999). Dialectical Behavior Therapy for Patients with Borderline Personality Disorder and Drug-Dependence. American Journal on Addictions, 8(4), 279-292. doi: $10.1080 / 105504999305686$

Lowe, A.L., \& Abou-Saleh, M.T. (2004). The British experience of dual diagnosis in the national health service. Acta Neuropsychiatrica, 16(1), 41-46. doi: 10.1111/j.16015215.2004.0060.x

Lydecker, K.P., Tate, S.R., Cummins, K.M., McQuaid, J., Granholm, E., \& Brown, S.A. (2010). Clinical Outcomes of an Integrated Treatment for Depression and Substance Use Disorders. Psychology of Addictive Behaviors, 24(3), 453-465. doi: $10.1037 / \mathrm{a} 0019943$

Lykke, J., Hesse, M., Austin, S. F., \& Oestrich, I. (2008). Validity of the BPRS, the BDI and the BAI in dual diagnosis patients. Addictive Behaviors, 33(2), 292-300. doi: 10.1016/j.addbeh.2007.09.020

Lyne, J.P., O’Donoghue, B., Clancy, M., \& O’Gara, C. (2011). Comorbid Psychiatric Diagnoses Among Individuals Presenting to an Addiction Treatment Program for Alcohol Dependence. Substance Use \& Misuse, 46(4), 351-358. doi: $10.3109 / 10826081003754757$ 
Martino, S., Carroll, K., Kostas, D., Perkins, J., \& Rounsaville, B. (2002). Dual Diagnosis Motivational Interviewing: A modification of Motivational Interviewing for substance-abusing patients with psychotic disorders. Journal of Substance Abuse Treatment, 23(4), 297-308. doi: 10.1016/S0740-5472(02)00295-7

Mazza, M., Mandelli, L., Di Nicola, M., Harnic, D., Catalano, V., Tedeschi, D., et al. (2009). Clinical features, response to treatment and functional outcome of bipolar disorder patients with and without co-occurring substance use disorder: 1-year follow-up. Journal of Affective Disorders, 115(1-2), 27-35. doi: 10.1016/j.jad.2008.08.019

McHugo, G.J., Drake, R.E., Burton, H.L., \& Ackerson, T.H. (1995). A Scale for Assessing the Stage of Substance Abuse Treatment in Persons with Severe Mental Illness. Journal of Nervous and Mental Disease, 183(12), 762-767. doi: 10.1097/00005053199512000-00006

Mueller, T., Lavori, P., Keller, M., Swartz, A., Warshaw, M., Hasin, D., et al. (1994). Prognostic effect of the variable course of alcoholism on the 10-year course of depression. American Journal of Psychiatry, 151(5), 701-706.

Mueser, K.T., Drake, R.E., \& Wallach, M.A. (1998). Dual diagnosis: A review of etiological theories. Addictive Behaviors, 23(6), 717-734.

Myrick, H., \& Brady, K. (2003). Current review of the comorbidity of affective, anxiety, and substance use disorders. Current Opinion in Psychiatry, 16(3), 261-270. doi: 10.1097/01.yco.0000069080.26384.d8

NICE. (2006). Bipolar disorder: The management of bipolar disorder in adults, children and adolescents, in primary and secondary care. London: National Institute of Clinical Excellence. Retrieved from http://guidance.nice.org.uk/CG38 
NICE. (2009). Treatment and management of depression in adults, including adults with a chronic physical health problem. London: National Institute of Clinical Excellence. Retrieved from http://guidance.nice.org.uk/CG90

Nidecker, M., DiClemente, C.C., Bennett, M. E., \& Bellack, A.S. (2008). Application of the Transtheoretical Model of change: Psychometric properties of leading measures in patients with co-occurring drug abuse and severe mental illness. Addictive Behaviors, 33(8), 1021-1030. doi: 10.1016/j.addbeh.2008.03.012

Nomarniukor, N., \& Brown, E.S. (2009). Attrition factors in clinical trials of comorbid bipolar and substance-related disorders. Journal of Affective Disorders, 112(1-3), 284288. doi: 10.1016/j.jad.2008.04.016

Nunes, E.V., \& Levin, F.R. (2004). Treatment of Depression in Patients With Alcohol or Other Drug Dependence: A Meta-analysis. Journal of the American Medical Association, 291(15), 1887-1896. doi: 10.1001/jama.291.15.1887

Osilla, K.C., Hepner, K.A., Munoz, R.F., Woo, S., \& Watkins, K. (2009). Developing an integrated treatment for substance use and depression using cognitive-behavioral therapy. Journal of Substance Abuse Treatment, 37(4), 412-420. doi: 10.1016/j.jsat.2009.04.006

Ostacher, M.J., Perlis, R.H., Nierenberg, A.A., Calabrese, J., Stange, J.P., Salloum, I., et al. (2010). Impact of Substance Use Disorders on Recovery From Episodes of Depression in Bipolar Disorder Patients: Prospective Data From the Systematic Treatment Enhancement Program for Bipolar Disorder (STEP-BD). American Journal of Psychiatry, 167(3), 289-297. doi: 10.1176/appi.ajp.2009.09020299

Petersen, C.L., \& Zettle, R.D. (2009). Treating Inpatients With Comorbid Depression and Alcohol Use Disorders: A Comparison of Acceptance and Commitment Therapy Versus Treatment as Usual. The Psychological Record, 59(4), 521-536. 
Ramsey, S.E., Brown, R.A., Stuart, G.L., Burgess, E.S., \& Miller, I.W. (2002). Cognitive Variables in Alcohol Dependent Patients with Elevated Depressive Symptoms: Changes and Predictive Utility as a Function of Treatment Modality. Substance Abuse, 23(3), 171-182. doi: 10.1023/A:1019856823496

Reedy, A.R., \& Hall, J.A. (2008). Treatment issues with substance use disorder clients who have mood or anxiety disorders. Mental Health and Substance Use: Dual Diagnosis, l(1), 44-53. doi: 10.1080/17523280701741738

Regier, D.A., Farmer, M.E., Rae, D.S., Locke, B.Z., Keith, S.J., Judd, L.L., et al. (1990). Comorbidity of Mental Disorders With Alcohol and Other Drug Abuse. Journal of the American Medical Association, 264(19), 2511-2518. doi: 10.1001/jama.1990.03450190043026

Richardson, T. (2011). Correlates of Substance Use Disorder in Bipolar Disorder: A Systematic Review and Meta-Analysis. Mental Health and Substance Use: Dual Diagnosis, 4(3), 239-255. doi: 10.1080/17523281.2011.578583

Richardson, T., \& Garavan, H. (2011). Relationships between substance use and hypomanic symptoms in a non-clinical sample. Mental Health and Substance Use: Dual Diagnosis, 4(3), 211-221. doi: 10.1080/17523281.2010.509845

Rosenberg, S.D., Drake, R.E., Wolford, G.L., Mueser, K.T., Oxman, T.E., Vidaver, R.M., et al. (1998). Dartmouth Assessment of Lifestyle Instrument (DALI): A Substance Use Disorder Screen for People With Severe Mental Illness. American Journal of Psychiatry, 155(2), 232-238.

Schmitz, J.M., Averill, P., Sayre, S., McCleary, P., Moeller, F.G., \& Swann, A. (2002). Cognitive-Behavioral Treatment of Bipolar Disorder and Substance Abuse: A Preliminary Randomized Study. Addictive Disorders \& Their Treatment, 1(1), 17-24. 
Schuckit, M., Tipp, J., Bergman, M., Reich, W., Hesselbrock, V., \& Smith, T. (1997). Comparison of induced and independent major depressive disorders in 2,945 alcoholics. American Journal of Psychiatry, 154(7), 948-957.

Shan, C., Lee, S.-Y., Chang, Y.-H., Wu, J.Y.-W., Chen, S.-L., Chen, S.-H., et al. (2011). Neuropsychological functions in Han Chinese patients in Taiwan with bipolar II disorder comorbid and not comorbid with alcohol abuse/alcohol dependence disorder. Progress in Neuro-Psychopharmacology and Biological Psychiatry, 35(1), 131-136. doi: 10.1016/j.pnpbp.2010.10.004

Stein, M.D., Herman, D.S., Solomon, D.A., Anthony, J.L., Anderson, B.J., Ramsey, S.E., et al. (2004). Adherence to treatment of depression in active injection drug users: The minerva study. Journal of Substance Abuse Treatment, 26(2), 87-93. doi: $10.1016 / \mathrm{S} 0740-5472(03) 00160-0$

Strakowski, S.M., \& DelBello, M.P. (2000). The co-occurrence of bipolar and substance use disorders. Clinical Psychology Review, 20(2), 191-206. doi: 10.1016/S02727358(99)00025-2

Swanson, A.J., Pantalon, M.V., \& Cohen, K.R. (1999). Motivational Interviewing and Treatment Adherence among Psychiatric and Dually Diagnosed Patients. The Journal of Nervous and Mental Disease, 187(10), 630-635. doi: 10.1016/S02727358(99)00025-2

Tate, S. R., Wu, J., McQuaid, J. R., Cummins, K., Shriver, C., Krenek, M., et al. (2008). Comorbidity of substance dependence and depression: role of life stress and selfefficacy in sustaining abstinence. Psychology of Addictive Behaviors, 22(1), 47-57. doi: 10.1037/0893-164X.22.1.47 
Tiet, Q. Q., \& Mausbach, B. (2007). Treatments for patients with dual diagnosis: A review. Alcoholism: Clinical and Experimental Research, 31(4), 513-536. doi: $10.1111 / \mathrm{j} .1530-0277.2007 .00336 . x$

Torrens, M., Fonseca, F., Mateu, G., \& Farré, M. (2005). Efficacy of antidepressants in substance use disorders with and without comorbid depression: A systematic review and meta-analysis. Drug and Alcohol Dependence, 78(1), 1-22. doi: 10.1016/j.drugalcdep.2004.09.004

van den Bosch, L.M.C., Verheul, R., Schippers, G.M., \& van den Brink, W. Dialectical Behavior Therapy of borderline patients with and without substance use problems: Implementation and long-term effects. Addictive Behaviors, 27(6), 911-923. doi: 10.1016/S0306-4603(02)00293-9

Van Laar, M., Van Dorsselaer, S., Monshouwer, K., \& De Graaf, R. (2007). Does cannabis use predict the first incidence of mood and anxiety disorders in the adult population? Addiction, 102(8), 1251-1260. doi: 10.1111/j.1360-0443.2007.01875.x

van Rossum, I., Boomsma, M., Tenback, D., Reed, C., van Os, J., \& the Emblem Advisory Board. (2009). Does Cannabis Use Affect Treatment Outcome in Bipolar Disorder?: A Longitudinal Analysis. The Journal of Nervous and Mental Disease, 197(1), 35-40. doi: 10.1097/NMD.0b013e31819292a6

Warren, J.I., Stein, J.A., \& Grella, C.E. (2007). Role of social support and self-efficacy in treatment outcomes among clients with co-occurring disorders. Drug and Alcohol Dependence, 89(2-3), 267-274. doi: 10.1016/j.drugalcdep.2007.01.009

Watkins, K.E., Hunter, S. B., Burnam, M.A., Pincus, H.A., \& Nicholson, G. (2005). Review of treatment recommendations for persons with a co-occurring affective or anxiety and substance use disorder. Psychiatric Services, 56(8), 913-926. 
Weaver, T., Madden, P., Charles, V., Stimson, G., Renton, A., Tyrer, P., et al. (2003). Comorbidity of substance misuse and mental illness in community mental health and substance misuse services. British Journal of Psychiatry, 183(4), 304-313. doi: 10.1192/bjp.183.4.273-a15

Weber, B., Jermann, F., Gex-Fabry, M., Nallet, A., Bondolfi, G., \& Aubry, J. M. (2010). Mindfulness-based cognitive therapy for bipolar disorder: A feasibility trial. European Psychiatry, 25(6), 334-337. doi:10.1192/bjp.183.4.273-a15

Weiss, R.D. (2004). Treating patients with bipolar disorder and substance dependence: Lessons learned. Journal of Substance Abuse Treatment, 27(4), 307-312. doi: 10.1016/j.jsat.2004.10.001

Weiss, R.D., Greenfield, S.F., Griffin, M.L., Najavits, L.M., \& Fucito, L.M. (2000). The use of collateral reports for patients with bipolar and substance use disorders. American Journal of Drug and Alcohol Abuse, 26(3), 369-378.

Weiss, R.D., Griffin, M.L., Greenfield, S.F., Najavits, L.M., Wyner, D., Soto, J.A., et al. (2000). Group therapy for patients with bipolar disorder and substance dependence: Results of a pilot study. Journal of Clinical Psychiatry, 61(5), 361-367.

Weiss, R.D., Griffin, M.L., Jaffee, W.B., Bender, R.E., Graff, F.S., Gallop, R.J., et al. (2009). A "community-friendly" version of integrated group therapy for patients with bipolar disorder and substance dependence: A randomized controlled trial. Drug and Alcohol Dependence, 104(3), 212-219. doi: 10.1016/j.drugalcdep.2009.04.018

Weiss, R.D., Griffin, M.L., Kolodziej, M.E., Greenfield, S.F., Najavits, L.M., Daley, D.C., et al. (2007). A randomized trial of integrated group therapy versus group drug counseling for patients with bipolar disorder and substance dependence. American Journal of Psychiatry, 164(1), 100-107. doi: 10.1176/appi.ajp.164.1.100 
Weiss, R.D., Kolodziej, M., Griffin, M.L., Najavits, L.M., Jacobson, L.M., \& Greenfield, S. F. (2004). Substance use and perceived symptom improvement among patients with bipolar disorder and substance dependence. Journal of Affective Disorders, 79(1-3), 279-283. doi: 10.1016/S0165-0327(02)00454-8

Weiss, R.D., Najavits, L.M., \& Greenfield, S.F. (1999). A relapse prevention group for patients with bipolar and substance use disorders. Journal of Substance Abuse Treatment, 16(1), 47-54. doi: 10.1016/S0740-5472(98)00011-7

Weiss, R.D., Najavits, L.M., Greenfield, S.F., Soto, J.A., Shaw, S.R., \& Wyner, D. (1998). Validity of substance use self-reports in dually diagnosed outpatients. American Journal of Psychiatry, 155(1), 127-128.

Weiss, R.D., Ostacher, M.J., Otto, M.W., Calabrese, J.R., Fossey, M., Wisniewski, S.R., et al. (2005). Does recovery from substance use disorder matter in patients with bipolar disorder? Journal of Clinical Psychiatry, 66(6), 730-735.

Westreich, L., Guedj, P., Galanter, M., \& Baird, D. (1997). Differences between men and women in dual-diagnosis treatment. American Journal on Addictions, 6(4), 311-317. doi: 10.1111/j.1521-0391.1997.tb00412.x

Whicher, E., \& Abou-Saleh, M. (2007). Bipolar affective disorder and drug and alcohol problems. In A. V. Baker \& R. Velleman (Eds.), Clinical handbook of co-existing mental health and drug and alcohol problems. (pp. 267-289). New York: Routledge/Taylor \& Francis Group.

Williams, J.M.G., Alatiq, Y., Crane, C., Barnhofer, T., Fennell, M.J.V., Duggan, D.S., et al. (2008). Mindfulness-based Cognitive Therapy (MBCT) in bipolar disorder: Preliminary evaluation of immediate effects on between-episode functioning. Journal of Affective Disorders, 107(1), 275-279. doi: 10.1016/j.jad.2007.08.022 
Yaldizli, O., Kuhl, H.C., Graf, M., Wiesbeck, G.A., \& Wurst, F.M. (2010). Risk factors for suicide attempts in patients with alcohol dependence or abuse and a history of depressive symptoms: A subgroup analysis from the WHO/ISBRA study. Drug and Alcohol Review, 29(1), 64-74. doi: 10.1111/j.1465-3362.2009.00089.x 